\title{
Short communication: Artificial ultraviolet B light exposure increases vitamin $D$ levels in cow plasma and milk
}

\author{
Jette Jakobsen, ${ }^{* 1}$ Søren Krogh Jensen, $†$ Lone Hymøller, $†$ Elisabeth Wreford Andersen, $\ddagger$ Poul Kaas,§ \\ Anders Burild, * and Rie Bak Jäpelt* \\ *National Food Institute, Technical University of Denmark, 2860 Søborg, Denmark \\ †Department of Animal Science, Aarhus University, 8830 Tjele, Denmark \\ ‡Department of Applied Mathematics and Computer Science, Technical University of Denmark, 2800 Lyngby, Denmark \\ $\S$ Scan Research, 7400 Herning, Denmark
}

\begin{abstract}
The number of dairy cows without access to pasture or sunlight is increasing; therefore, the content of vitamin D in dairy products is decreasing. Ultimately, declining vitamin $\mathrm{D}$ levels in dairy products will mean that dairy products are a negligible source of natural vitamin $\mathrm{D}$ for humans. We tested the ability of a specially designed UVB lamp to enhance the vitamin $\mathrm{D}_{3}$ content in milk from dairy cows housed indoors. This study included 16 cows divided into 4 groups. Each group was exposed daily to artificial UVB light simulating $1,2,3$, or $4 \mathrm{~h}$ of summer sun at $56^{\circ} \mathrm{N}$ for $24 \mathrm{~d}$, and the group with simulated exposure to $2 \mathrm{~h}$ of summer sun daily continued to be monitored for $73 \mathrm{~d}$. We found a significant increase in 25-hydroxyvitamin $\mathrm{D}_{3}$ $\left(25 \mathrm{OHD}_{3}\right)$ levels in plasma as well as vitamin $\mathrm{D}_{3}$ and $25 \mathrm{OHD}_{3}$ levels in milk after daily exposure for $24 \mathrm{~d}$ in all treatment groups. Extending daily exposure to artificial UVB light to $73 \mathrm{~d}$ did not lead to an increase of vitamin $\mathrm{D}_{3}$ or $25 \mathrm{OHD}_{3}$ level in the milk. In conclusion, the change in production facilities for dairy cows providing cows with no access to pasture and sunlight causes a decrease of vitamin D levels in dairy products. This decrease may be prevented by exposing cows to artificial UVB light in the stable.
\end{abstract}

Key words: vitamin D, artificial UVB exposure, cow milk

\section{Short Communication}

The metabolic active form of vitamin $\mathrm{D}, 1,25$-dihydroxyvitamin $\mathrm{D}$, is essential for regulating the levels of calcium and phosphorus in vertebrates; in addition, vitamin D insufficiency has been linked to an increased risk of hypertension, autoimmune diseases, diabetes,

Received December 22, 2014.

Accepted May 11, 2015.

${ }^{1}$ Corresponding author: jeja@food.dtu.dk and cancer (DeLuca, 2004). Cutaneous synthesis of vitamin $\mathrm{D}_{3}$ is considered the major source of vitamin $\mathrm{D}$, but sun exposure is limited during winter at northern latitudes and intake from food becomes essential (Madsen et al., 2013).

Generally, fatty fish have the highest natural content of vitamin D and are regarded as an important source of vitamin D. Meat and dairy products have lower contents of vitamin $\mathrm{D}$ than fish, but a high intake of meat and dairy products is typical in a Western diet; consequently, their contribution to the total vitamin D intake is significant despite their low content of vitamin D. In Denmark, cow milk contributes approximately $12 \%$ of the total vitamin $\mathrm{D}$ intake via consumption of milk, cheese, and other dairy products (Pedersen et al., 2010). Mandatory or voluntary fortification of, for example, milk and margarine are implemented in some countries, but in other countries (e.g., Denmark), fortification with vitamin $\mathrm{D}$ is negligible. Two primary sources of vitamin D exist for cows: cholecalciferol (vitamin $\mathrm{D}_{3}$ ) provided in the feed or produced endogenously in animals by UVB exposure of 7-dehydrocholesterol in the skin. Bio-fortification strategies for vitamin D optimize these natural processes to increase the content of vitamin $\mathrm{D}$ in food products eaten by consumers.

Several factors influence the synthesis of vitamin $\mathrm{D}_{3}$ in the skin. In cows, vitamin $\mathrm{D}_{3}$ synthesis in the skin derived from sun exposure has been shown to be independent of hair coverage but does depend on the duration of light exposure (Hymøller and Jensen, 2010, 2012). In addition, season and latitude influence the synthesis of vitamin $\mathrm{D}_{3}$ in the skin. In dairy cows, vitamin $\mathrm{D}_{3}$ supplementation increases vitamin $\mathrm{D}_{3}$ status during the winter but has no effect during the summer if the cows have access to pasture (Hymøller et al., 2009). Observational studies have shown seasonal variations, with the maximum level of vitamin D in milk being detected during the summer (Chick and Roscoe, 1926; Bechtel and Hoppert, 1936). Similarly, vitamin $\mathrm{D}_{3}$ levels in milk from cows in New Zealand grazing on pastures 
year round were highest in the summer (Kurmann and Indyk, 1994). Whole milk derived from organic cows in the winter, when cows are housed in stables, bought on the Danish market, showed a vitamin D content that was 6 times lower compared with that of whole milk bought during the summer, when the cows are, by regulation, on pasture (Jakobsen and Saxholt, 2009). Studies of human breast milk have provided further evidence for the association between sunlight exposure and vitamin $\mathrm{D}_{3}$ content in milk (Greer et al., 1984; Ala-Houhala et al., 1988).

In Denmark, the number of dairy cows without access to pasture has increased as dairy farming has become more efficient (Knowledge Center for Agriculture, 2014). However, the current vitamin D recommendation is based on access to pasture. Ultimately, declining vitamin $\mathrm{D}$ levels in dairy products will transform dairy products to a negligible source of natural vitamin $\mathrm{D}$ for consumers. In this study, we tested the efficacy of a lamp specifically constructed to increase vitamin $\mathrm{D}_{3}$ synthesis. The lamp was developed to mimic the sun to enhance the natural synthesis of vitamin $\mathrm{D}_{3}$ in cows with no access to sunlight. Our objective was to produce milk that had levels of vitamin D similar to or higher than that of milk derived from dairy cows with access to pasture. In addition, our intention was to benefit the cows, so we included measurements of vitamin $\mathrm{D}_{3}$ status. The determination of other endpoints used to analyze the health of the dairy cows was outside the scope of this study due to economic constraints.

The current study complied with the Danish Ministry of Justice Law No. 1306 (November 23, 2007) concerning experiments with animals and the care of animals used for experimental purposes. This study was designed to assess the effect of daily exposure to an artificial UVB light source for 30, 60, 90, and $120 \mathrm{~min}$, which imitated sun exposure comparable to approximately 1, 2, 3, and $4 \mathrm{~h}$ of summer sun at $56^{\circ} \mathrm{N}$, respectively, on vitamin $\mathrm{D}_{3}, 25$-hydroxyvitamin $\mathrm{D}_{3}\left(25 \mathrm{OHD}_{3}\right)$, and fat contents in cow milk as well as on the $25 \mathrm{OHD}_{3}$ level in plasma. Sixteen dairy cows of the black and white Danish Holstein breed were included in this study and divided into 4 treatment groups, with 4 cows in each group.

Coat color of the cows was assessed as the percentage of black coat area visually estimated from photographic silhouettes of the cows from different angles (Sneddon et al., 2004). Before inclusion in the treatment groups, cows were deprived of vitamin $\mathrm{D}_{3}$ in their diet for 6 mo and had no access to sun exposure during this period. The exception, for practical reasons, was that cows exposed to artificial UVB light for 60 min daily, simulating $2 \mathrm{~h}$ of summer sun, had been provided feed with vitamin $\mathrm{D}_{3}$ until a couple of months before the start of the experiment.
During the study, all cows were housed in a tie stable with slatted floors and fed ad libitum with a maize-, clover grass-, and rye silage-based TMR void of vitamin $\mathrm{D}_{3}$. Feeding took place once a day at $0900 \mathrm{~h}$, and milking was carried out twice a day at 0600 and $1700 \mathrm{~h}$. The study was carried out between July and November 2011 at Aarhus University, Department of Animal Science (Tjele, Denmark).

The lamp applied in this study was developed specifically to simulate the sun and to provide the wavelengths necessary for conversion of 7-dehydrocholesterol to vitamin $\mathrm{D}_{3}$ in the skin of the dairy cows; wavelengths ranged from 280 to $415 \mathrm{~nm}$. An OL 756 spectroradiometer (Optronics Laboratories, Orlando, FL) was used to scan the light emitted from the lamp from 250 to 400 $\mathrm{nm}$ with 1-nm increments to calculate the erythema dose according to the Erythema Reference Action Spectrum and Standard Erythema Dose (SED; ISO/CIE Standard ISO 17166:1999/CIE S 007-1998; ISO, 1999). One SED was defined as $100 \mathrm{~J} / \mathrm{m}^{2}$ (Diffey et al., 1997). The lamp was situated at a distance of $3.5 \mathrm{~m}$ from the cows, and 30, 60, 90, and $120 \mathrm{~min}$ of artificial UVB light exposure was calculated to equal $1,2,3$, and $4 \mathrm{~h}$, respectively, of full body exposure of midday summer sun at $56^{\circ} \mathrm{N}$ (Bogh et al., 2012).

The duration of the study was $24 \mathrm{~d}$ for the groups simulating 1,3 , and $4 \mathrm{~h}$ of sunlight, whereas it was extended to $73 \mathrm{~d}$ for the group exposed daily to artificial UVB light simulating $2 \mathrm{~h}$ of sunlight. Every day, each of the cows was positioned in front of the lamp at a distance of approximately $3.5 \mathrm{~m}$ for the designated duration of exposure. The cows' heads were facing opposite the lamp.

Throughout the study period, milk and blood were collected from the cows. Milk samples were collected in vacuum buckets, and the milk was stirred before sampling an aliquot of a minimum of $250 \mathrm{~mL}$. Sampling was done before the first artificial UVB light exposure (d 0) and at d 24 for all groups; sample collection was repeated on $\mathrm{d} 3,10,17$, and weekly thereafter until d 73 for the cows exposed to the artificial UVB light daily for 60 min. Plasma samples were obtained from blood collected from the tail vein in sodium heparin-coated Vacutainer tubes (Becton, Dickinson Co., Franklin Lakes, NJ) between 0830 and $0930 \mathrm{~h}$ on d 0 before artificial UVB light treatment and subsequently every 3 to $4 \mathrm{~d}$. All samples of milk and plasma were stored at $-18^{\circ} \mathrm{C}$ or below until analysis.

The analyses of vitamin $\mathrm{D}_{3}$ and the metabolite $25 \mathrm{OHD}_{3}$ were performed by using a method including saponification and liquid/liquid extraction (Jakobsen et al., 2004; Jakobsen and Saxholt, 2009), followed by quantification by electrospray ionization tandem mass spectrometry as described previously (Jäpelt et al., 
2013). Aliquots of $25 \mathrm{~g}( \pm 1 \mathrm{~g})$ of milk were taken for analyses. The content of fat in the milk was determined by the gravimetric method, according to a modified Schmid-Bondzynski-Ratslaff procedure (NMKL, 1989). In the laboratory at the Department of Animal Science, Aarhus University (Tjele, Denmark), the content of $25 \mathrm{OHD}_{3}$ in plasma was assessed in $1.5 \mathrm{~mL}$ of plasma by a method described elsewhere (Hymøller and Jensen, 2011).

Statistical analysis was performed with SAS software (SAS Institute Inc., Cary, NC). To examine the effect of the artificial UVB light exposure, paired $t$-tests were used, whereas one-way ANOVA was used to test the differences between the treatment groups. A repeatedmeasures model was fitted to compare the estimated level at d 24 to the estimated maximum level attained. The number of days of artificial UVB light exposure and coat color were included as factors in the model. Observations from the same cow could not be assumed to be independent, and they were modeled using a first-order autoregressive moving-average correlation structure. Finally, linear normal regression models were fitted to test the association between $25 \mathrm{OHD}_{3}$ in plasma and vitamin $\mathrm{D}$ metabolites in the milk. The vitamin D metabolite and fat levels are given as mean \pm standard error of the mean (SEM).

The effects of 30,90 , or $120 \mathrm{~min}$ of daily exposure to a UVB lamp for $24 \mathrm{~d}$ on levels of vitamin $\mathrm{D}_{3}, 25 \mathrm{OHD}_{3}$, and percentage fat in milk are shown in Figure 1. From d 0 to 24, the artificial UVB light exposure was found to generate a significant increase in vitamin $\mathrm{D}_{3}$ and $25 \mathrm{OHD}_{3}$ levels in milk for all treatment groups. For fat content, no effect was found in the 30- and 90-min groups, but a slight decrease was seen in the 120-min group from d 0 until 24.

For the level of $25 \mathrm{OHD}_{3}$ in milk compared with that in plasma at $\mathrm{d} 24$, the regression of $25 \mathrm{OHD}_{3}$ in milk on $25 \mathrm{OHD}_{3}$ in plasma was significant $(P=0.03)$, with a slope of 0.11 (95\% CI: $0.01-0.20)$, whereas no association was found at d $0(P=0.99)$. For the level of vitamin $\mathrm{D}_{3}$ in milk versus that in plasma, no statistically significant association on d 0 or 24 was found $(P$ $=0.28$ and 0.08 , respectively).

As shown in Figure 2, the levels of $25 \mathrm{OHD}_{3}$ in plasma at d 0 and 24 revealed a significant effect of the artificial UVB light exposure in all treatment groups $(P$ $=0.0073$ for $30 \mathrm{~min}, P=0.0105$ for $90 \mathrm{~min}$, and $P=$ 0.0064 for $120 \mathrm{~min}$ ). A significant difference was shown between the groups, as the cows exposed to the UVB lamp for 90 and 120 min daily showed higher vitamin D levels than the cows exposed for 30 min daily $(P=$ 0.001).

The effects of 60-min daily lamp exposure for $73 \mathrm{~d}$ on the levels of vitamin $\mathrm{D}_{3}, 25 \mathrm{OHD}_{3}$, and percentage fat
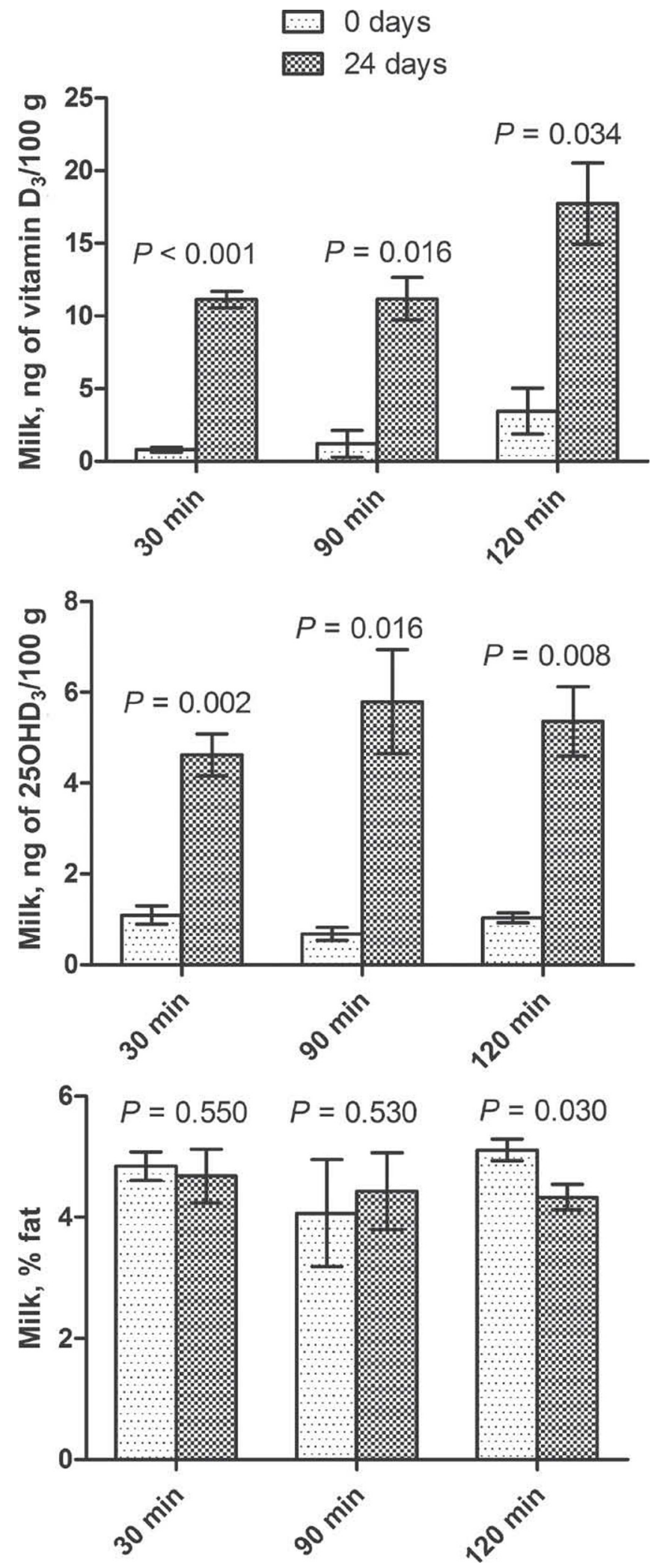

Figure 1. Content of vitamin $\mathrm{D}_{3}, 25$-hydroxyvitamin $\mathrm{D}_{3}$, and fat in milk sampled at $\mathrm{d} 0$ and 24 (mean \pm SEM) from cows $(\mathrm{n}=4$ in each group) exposed to a UVB lamp daily for 30,90 , or $120 \mathrm{~min}$. The $P$-values originate from paired $t$-tests comparing d 0 with d 24 . 
in milk are shown in Figure 3. In milk, a statistically significant increase from d 0 to 24 was shown for vitamin $\mathrm{D}_{3}(P=0.029)$, but not for $25 \mathrm{OHD}_{3}(P=0.089)$ or percentage fat $(P=0.971)$. A repeated-measures model was fitted to compare the estimated level at $\mathrm{d} 24$ to the estimated maximum level attained during $73 \mathrm{~d}$ of exposure. No significant difference was found between the estimated maximum level and the level on d 24 in milk for vitamin $\mathrm{D}_{3}(P=0.40), 25 \mathrm{OHD}_{3}(P=0.087)$, or fat $(P=0.074)$. However, we did detect a statistically significant increase in plasma $25 \mathrm{OHD}_{3}$ from d 0 to $24(P=0.0017)$ and a further increase until d $73(P<$ 0.001 ), with an estimated maximum at d 64 (Figure 4).

In commercial milk, levels of vitamin $\mathrm{D}_{3}$ and $25 \mathrm{OHD}_{3}$ have been shown to be correlated with fat content (Jakobsen and Saxholt, 2009). However, in this study, the percentage of fat in the milk was not a determinant for the content of vitamin $\mathrm{D}_{3}$. In another study using exclusively pasture-grazed cows, vitamin $\mathrm{D}_{3}$ levels were also shown to be independent of the proportion of fat in the milk (Kurmann and Indyk, 1994). This difference in fat content is probably due to the cow's natural variation in milk production and not to the production and separation of the milk into skimmed and whole milk.
The UVB lamp used in this study was developed to stimulate cutaneous synthesis of vitamin $\mathrm{D}_{3}$ in vertebrate animals. Cutaneous vitamin $\mathrm{D}_{3}$ synthesis can be stimulated by irradiation of the skin to artificial UVB light, which has been shown previously in pigs (Cooper et al., 1997) and humans (Greer et al., 1984; Bogh et al., 2012). The maximum synthesis of the vitamin $\mathrm{D}_{3}$ precursor previtamin $\mathrm{D}_{3}$ in the skin occurs at 295 to 300 $\mathrm{nm}$. Monochromatic UV light at $295 \mathrm{~nm}$ and sunlight are reported to cause different degradation profiles of previtamin $\mathrm{D}_{3}$ to lumisterol and tachysterol, probably because of the different UV absorption spectra of these compounds (MacLaughlin et al., 1982). To mimic solar synthesis, we developed and selected a broadband UVB light source.

We showed a significant increase in the vitamin $\mathrm{D}_{3}$ and $25 \mathrm{OHD}_{3}$ levels in the milk from cows exposed to UVB light for $24 \mathrm{~d}$ compared with d 0 (Figure 1). The artificial UVB light exposure, which simulated summer sun at $56^{\circ} \mathrm{N}$ for approximately $4 \mathrm{~h}$ daily for $24 \mathrm{~d}$, resulted in $18 \pm 6 \mathrm{ng}$ of vitamin $\mathrm{D}_{3} / 100 \mathrm{~g}$ of milk and $5 \pm 2$ ng of $25 \mathrm{OHD}_{3} / 100 \mathrm{~g}$ of milk. These levels are similar to the contents reported by Jakobsen and Saxholt (2009) in Danish milk, which showed a maximum content of $19 \mathrm{ng}$ of vitamin $\mathrm{D}_{3}$ and $8 \mathrm{ng}$ of $25 \mathrm{OHD}_{3}$ per $100 \mathrm{~g}$ of

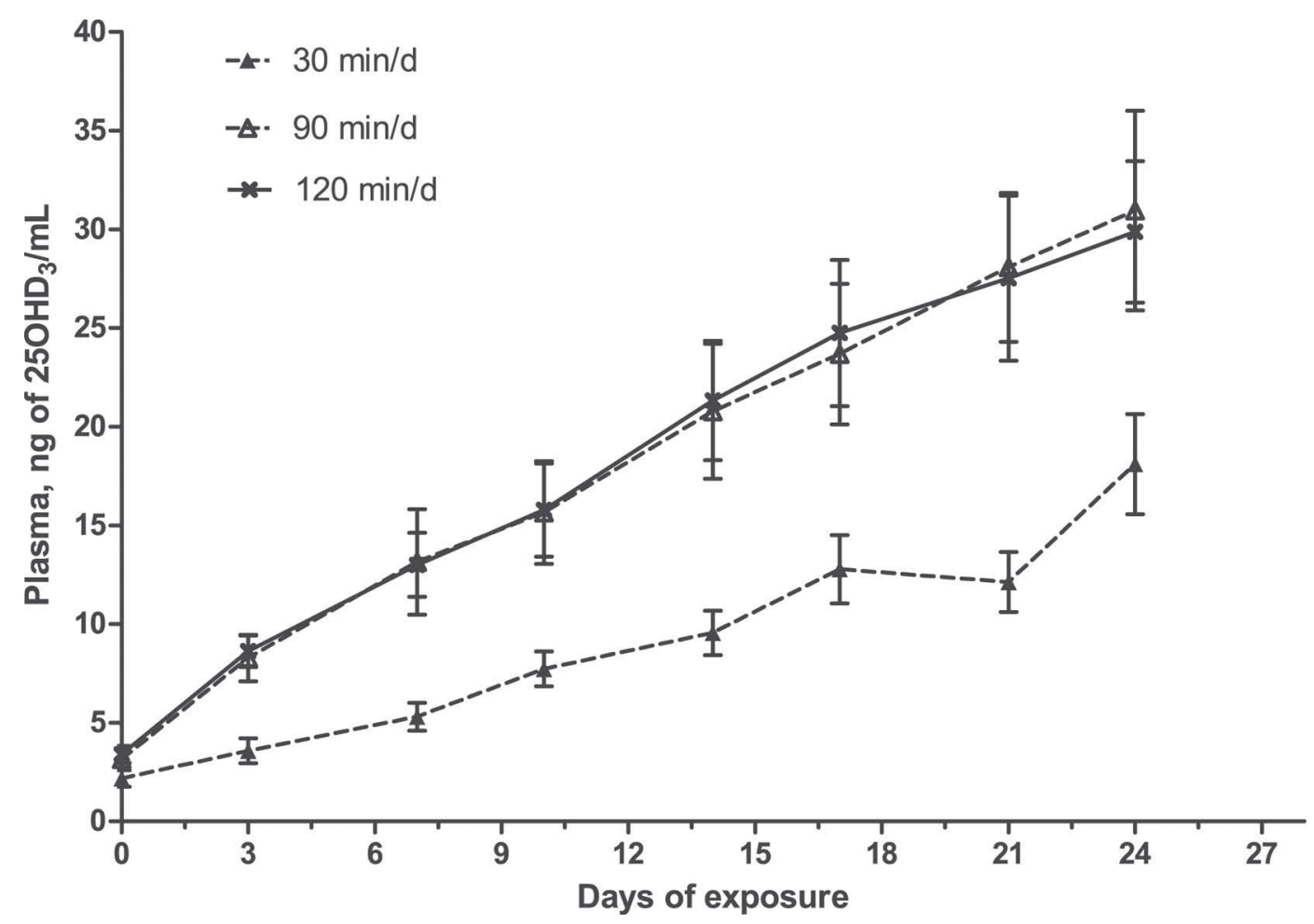

Figure 2. Vitamin D (mean \pm SEM) in plasma of cows $(n=4$ in each group) exposed daily to the UVB lamp for 30,90 , or 120 min. We detected a significant difference between d 0 and $24(P=0.0073,0.0105$, and 0.0064 , respectively). 
whole milk (containing 3.5\% fat). Kurmann and Indyk (1994) found a maximum of $27 \mathrm{ng}$ of vitamin $\mathrm{D}_{3} / 100$ $\mathrm{mL}$ in milk from New Zealand, but they did not quantify $25 \mathrm{OHD}_{3}$. We sought to determine if we had reached a steady-state vitamin $\mathrm{D}_{3}$ level after $24 \mathrm{~d}$ of artificial UVB light exposure by extending the daily exposure of 60 min (similar to $2 \mathrm{~h}$ of summer sunlight) from 24 to $73 \mathrm{~d}$. We observed no significant increase in the vitamin $\mathrm{D}_{3}$ and $25 \mathrm{OHD}_{3}$ levels in the milk (Figure 3 ). This finding underlines that exposing cows to artificial UVB light for $24 \mathrm{~d}$ is sufficient to obtain a maximum level of vitamin $\mathrm{D}$ in the milk.

Furthermore, we showed a significant increase in the plasma vitamin $\mathrm{D}_{3}$ level in cows exposed to artificial UVB light. By simulating 3 or $4 \mathrm{~h}$ of daily sun exposure with the lamp for $24 \mathrm{~d}$, the vitamin $\mathrm{D}_{3}$ level in the plasma increased to $30 \mathrm{ng}$ of $25 \mathrm{OHD}_{3} / \mathrm{mL}$ (Figure 2). This level was similar to that of cows grazing at pasture for 2.5 or $5 \mathrm{~h}$ daily during $24 \mathrm{~d}$ of Danish summer, which achieved vitamin D levels of 22 and $36 \mathrm{ng} / \mathrm{mL}$, respectively (Hymøller and Jensen, 2012). This comparison is strong because the 2 studies were performed in the same breed as used in this study-Danish Holstein - and both sets of analyses were run by the same laboratory.

However, we did not observe a steady state for vitamin D level in plasma after $24 \mathrm{~d}$ of daily artificial UVB light exposure for $60 \mathrm{~min}$; the data in Figure 4 show convergence toward a steady state after $24 \mathrm{~d}$. A maximum vitamin D level in plasma has been observed in humans and minipigs. In intervention studies of humans exposed to UV light or treated orally with different levels of vitamin $\mathrm{D}_{3}$, data have shown a similar maximum level of vitamin $\mathrm{D}$ that depends on the UV exposure period or oral dose (Heaney et al., 2003; Bogh et al., 2012); similar results have been found in minipigs (Burild et al., 2015).

In this study, we showed an association between plasma vitamin D level and milk $25 \mathrm{OHD}_{3}$ level. However, we did not identify an association between the level of vitamin D in plasma and that in milk. This finding is in contrast to studies in sows that were fed different levels of vitamin $\mathrm{D}_{3}$, in which an association was shown between plasma vitamin $\mathrm{D}$ level and milk vitamin $\mathrm{D}_{3}$ level in sow milk (Flohr et al., 2014; Weber et al., 2014).

The limited number of cows in each group was a limitation of this study. However, we showed the efficacy of artificial UVB exposure to increase vitamin $\mathrm{D}_{3}$ levels in milk and plasma to levels similar to those of cows grazing at pasture during the summer. Potentially, this process could be used in organic and conventional farming to ensure a high vitamin $\mathrm{D}$ level in cows raised indoors year round. In particular, this process will not
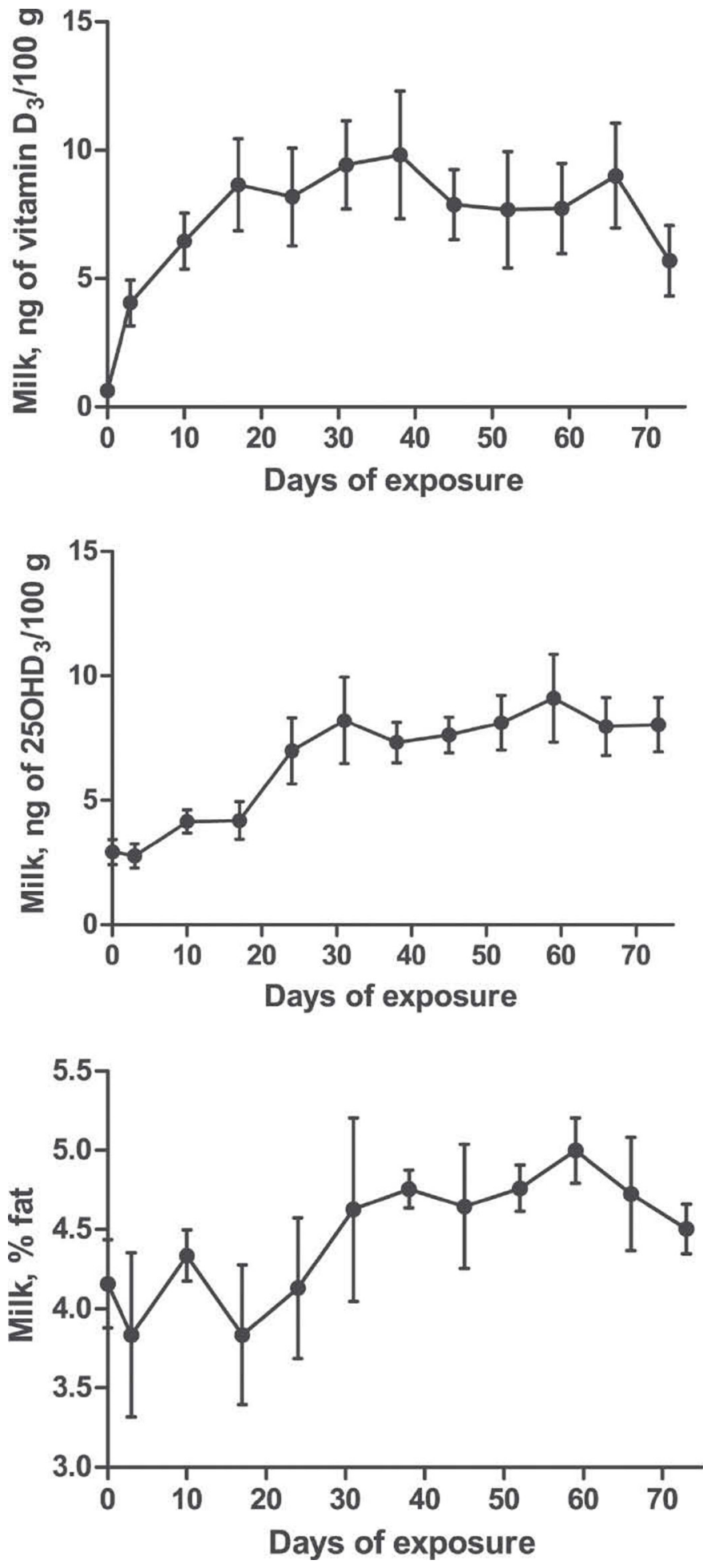

Figure 3. Vitamin $\mathrm{D}_{3}, 25$-hydroxyvitamin $\mathrm{D}_{3}$, and fat in milk sampled regularly from d 0 to 73 (mean \pm SEM) from cows $(n=4$ in this group) exposed daily to the UVB lamp for 60 min. Between $d$ 0 and 24 , a significant increase was shown for vitamin $\mathrm{D}_{3}$ in milk $(P$ $=0.029)$, but not for 25-hydroxyvitamin $\mathrm{D}_{3}$ and fat $(P=0.089$ and 0.971 , respectively). We detected no further increase between $\mathrm{d} 24$ and 73 for all compounds $(P<0.05)$. 


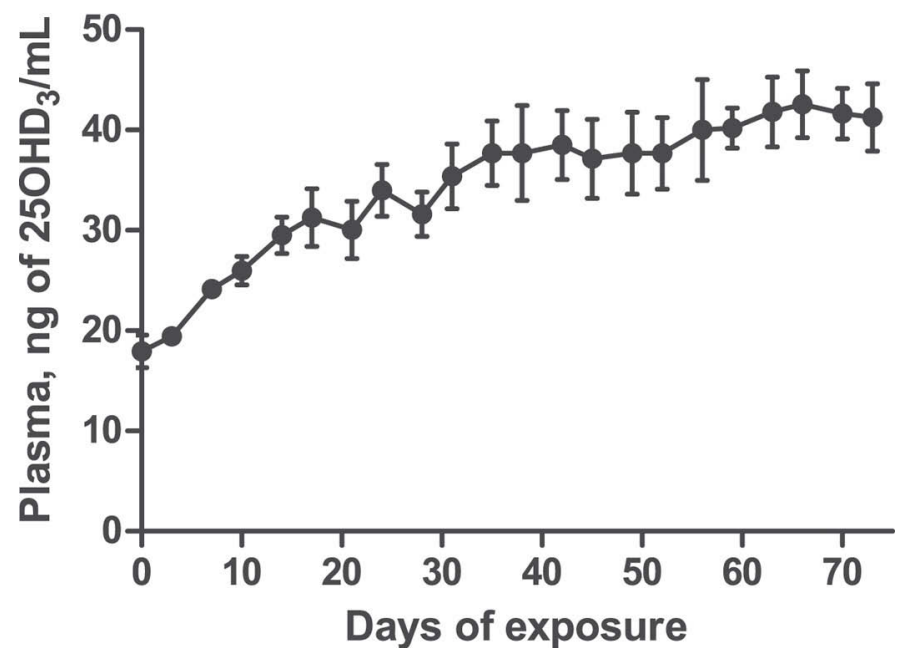

Figure 4. The vitamin $\mathrm{D}$ (mean \pm SEM) in the plasma of cows ( $\mathrm{n}=4$ in this group) exposed daily to the UVB lamp for $60 \mathrm{~min}$. We detected a significant increase between $\mathrm{d} 0$ and $24(P=0.0017)$ and a further increase to d $73(P<0.001)$.

cause any toxicity for the cows if we presume that the production of vitamin $\mathrm{D}_{3}$ in the cow's skin has similar metabolism as that in human skin (Webb and Holick, 1988).

We developed a light source for use in stables that emitted vitamin D-producing wavelengths together with light at higher wavelengths for normal lighting. At this stage, further development of the lamp prototype is necessary to make it suitable for industrial production of dairy products, thus enabling the cows to produce milk with the same high level of vitamin $D_{3}$ in the winter as in the summer. Further optimization of the artificial UVB light exposure is needed to secure a constant and high level of vitamin $\mathrm{D}_{3}$ in dairy products year round. We did not evaluate health benefits for the cows in this study, but a higher vitamin $\mathrm{D}_{3}$ status might reduce the requirement for phosphorous and reduce the risk of mastitis (Lippolis et al., 2011). Based on the findings of this study, exposing dairy cows to artificial UVB light would contribute to the health of people consuming dairy products and could improve the health of the cows by contributing to a general increase of the vitamin $\mathrm{D}_{3}$ level in the plasma. The production system would be in line with bio-fortification, as the increase of the content of vitamin $\mathrm{D}_{3}$ in dairy products is part of a natural production system. Because of the risk of skin cancer, humans are advised not to stay in the midday sun; therefore, it is essential to state that the artificial lighting system should be turned off during work hours. Dairy cows should not be exposed to a higher dose than cows grazing in the pasture during a summer day.

\section{ACKNOWLEDGMENTS}

This study was supported by The Danish Ministry of Food, Agriculture and Fisheries, Copenhagen (3412-082110), Mælkeafgiftsfonden (Viby J, Denmark), Århus University (Tjele, Denmark), and The Technical University of Denmark (Mørkhøj). These institutions had no involvement in the study design, data collection and analysis, or writing of this report.

\section{REFERENCES}

Ala-Houhala, M., T. Kostinen, M. T. Parviainen, and J. K. Visakorpi. 1988. 25-hydroxyvitamin D and vitamin D in human milk: Effects of supplementation and season. Am. J. Clin. Nutr. 48:1057-1060.

Bechtel, H. E., and C. A. Hoppert. 1936. A study of the seasonal variation of vitamin D in normal cow's milk. J. Nutr. 11:537-549.

Bogh, M. K., A. Schmedes, P. Philipsen, E. Thieden, and H. Wulf 2012. A small suberythemal ultraviolet B dose every second week is sufficient to maintain summer vitamin D levels: A randomized controlled trial. Br. J. Dermatol. 166:430-433.

Burild, A., H. L. Frandsen, M. Poulsen, and J. Jakobsen. 2015. Tissue content of vitamin $\mathrm{D}_{3}$ and 25 -hydroxy vitamin $\mathrm{D}_{3}$ in minipigs after cutaneous synthesis, supplementation and deprivation of vitamin $\mathrm{D}_{3}$. Steroids 98:72-79. http://dx.doi.org/10.1016/j. steroids.2015.02.017.

Chick, H., and M. H. Roscoe. 1926. Influence of diet and sunlight upon the amount of vitamin A and vitamin D in the milk afforded by a cow. Biochem. J. 20:632-649.

Cooper, D. A., D. A. Berry, V. A. Spendel, A. L. Kiorpes, and J. C. Peters. 1997. The domistic pig as a model for evaluation olestra's nutritional value. J. Nutr. 127:1555S-1565S.

DeLuca, H. F. 2004. Overview of general physiologic features and functions of vitamin D. Am. J. Clin. Nutr. 80:1689S-1696S.

Diffey, B. L., C. Jansen, F. Urbach, and H. Wulf. 1997. The standard erythema dose: A new photobiological concept. Photodermatol. Photoimmunol. Photomed. 13:64-66.

Flohr, J. R., M. D. Tokach, S. S. Dritz, J. M. DeRouchey, R. D. Goodband, J. L. Nelssen, and J. R. Bergstrom. 2014. An evaluation of the effects of added vitamin $\mathrm{D}_{3}$ in maternal diets on sow and pig performance. J. Anim. Sci. 92:594-603.

Greer, F. R., B. Hollis, D. J. Cripps, and R. C. Tsang. 1984. Effects of maternal ultraviolet-B irradiation on vitamin D content of human milk. J. Pediatr. 105:431-433.

Heaney, R. P., K. M. Davies, T. C. Chen, M. F. Holick, and M. J. Barger-Lux. 2003. Human serum 25-hydroxycholecalciferol response to extended oral dosing with cholecalciferol. Am. J. Clin. Nutr. 77:204-210.

Hymøller, L., and S. K. Jensen. 2010. Vitamin $\mathrm{D}_{3}$ synthesis in the entire skin surface of dairy cows despite hair coverage. J. Dairy Sci. 93:2025-2029.

Hymøller, L., and S. K. Jensen. 2011. Vitamin D analysis in plasma by high performance liquid chromatography (HPLC) with $\mathrm{C}(30)$ reversed phase column and UV detection-easy and acetonitrile-free. J. Chromatogr. A 1218:1835-1841.

Hymøller, L., and S. K. Jensen. 2012. 25-Hydroxycholecalciferol status in plasma is linearly correlated to daily summer pasture time in cattle at $56^{\circ} \mathrm{N}$. Br. J. Nutr. 108:666-671.

Hymøller, L., S. K. Jensen, H. Lindqvist, B. Johansson, M. O. Nielsen, and E. Nadeau. 2009. Supplementing dairy steers and organically managed dairy cows with synthetic vitamin $\mathrm{D}_{3}$ is unnecessary at pasture during exposure to summer sunlight. J. Dairy Res. $76: 372-378$.

ISO. 1999. ISO 17166: Erythema reference action spectrum and standard erythema dose. International Organization for Standardization (ISO), Geneva, Switzerland. 
Jakobsen, J., I. Clausen, T. Leth, and L. Ovesen. 2004. A new method for the determination of vitamin $\mathrm{D}_{3}$ and 25-hydroxyvitamin $\mathrm{D}_{3}$ in meat. J. Food Compos. Anal. 17:777-787.

Jakobsen, J., and E. Saxholt. 2009. Vitamin D metabolites in bovine milk and butter. J. Food Comp. Anal. 22:472-478.

Jäpelt, R. B., D. Silvestro, J. Smedsgaard, P. E. Jensen, and J. Jakobsen. 2013. Quantification of vitamin $\mathrm{D}_{3}$ and its hydroxylated metabolites in waxy leaf nightshade (Solanum glaucophyllum Desf.), tomato (Solanum lycopersicum L.) and bell pepper (Capsicum annuum L.). Food Chem. 138:1206-1211.

Knowledge Center for Agriculture. 2014. How many cows on pasture in Denmark? Accessed Jul. 16, 2014. http://www.vfl. dk/Afdelinger/Kvaeg/FaktaOmKvaegproduktion/Dyrevelfaerd/ Faktaomkoerpaagraes/hvor_mange_paa_graes.htm.

Kurmann, A., and K. Indyk. 1994. The endogenous vitamin D content of bovine milk: Influence of season. Food Chem. 50:75-81.

Lippolis, J. D., T. A. Reinhardt, R. A. Sacco, B. J. Nonnecke, and C. D. Nelson. 2011. Treatment of an intramammary bacterial infection with 25-hydroxyvitamin $\mathrm{D}_{3}$. PLoS ONE 6:e25479.

MacLaughlin, J. A., R. R. Anderson, and M. F. Holick. 1982. Spectral character of sunlight modulates photosynthesis of previtamin $\mathrm{D}_{3}$ and its photoisomers in human skin. Science 216:1001-1003.
Madsen, K. H., L. B. Rasmussen, R. Andersen, C. Mølgaard, J. Jakobsen, P. J. Bjerrum, and I. Tetens. 2013. Randomized controlled trial of the effects of vitamin D-fortified milk and bread on serum 25-hydroxyvitamin D concentrations in families in Denmark during winter: The VitmaD study. Am. J. Clin. Nutr. 98:374-382.

NMKL. 1989. Nordic Committee on Food Analysis. Method No. 131 Fat. Determination according to SBR in meat and meat products. Norwegian Veterinary Institute, Oslo, Norway.

Pedersen, A., S. Fagt, M. Groth, T. Christensen, A. Biltoft-Jensen, J. Matthiessen, and E. Trolle. 2010. Dietary Habits in Denmark 2003-2008. Main results. DTU Food, Moerkhoej Bygade, Soeborg, Denmark.

Sneddon, J. C., R. Walton, and A. Bond. 2004. A simple field technique for estimation of body surface area in horses and ponies. Equine Compar. Exerc. Physiol. 1:51-60.

Webb, A. R., and M. F. Holick. 1988. The role of sunlight in the cutaneous production of vitamin $\mathrm{D}_{3}$. Annu. Rev. Nutr. 8:375-399.

Weber, G. M., A.-K. M. Witschi, C. Wenk, and H. Martens. 2014 Effects of dietary 25-hydroxycholecalciferol and cholecalciferol on blood vitamin D and mineral status, bone turnover, milk composition, and reproductive performance of sows. J. Anim. Sci. 92:899-909. 